\title{
Fracture History in Osteoporosis: Risk Factors and its Effect on Quality of Life
}

\author{
Pınar Kuru ${ }^{1}$, Gülseren Akyüz ${ }^{2}$, Hülya Peynirci Cerşit ${ }^{2}$, Alp Eren Çelenlioğlu ${ }^{2}$, Ahmet Cumhur ${ }^{1}$, \\ Şefikcan Biricik ${ }^{1}$, Seda Kozan ${ }^{1}$, Aylin Gökşen ${ }^{1}$, Mikail Özdemir ${ }^{3}$, Emel Lüleci ${ }^{3}$ \\ ${ }^{1}$ Marmara University Faculty of Medicine, İstanbul, Turkey \\ ${ }^{2}$ Department of Physical Medicine and Rehabilitation, Marmara University Faculty of Medicine, İstanbul, Turkey \\ ${ }^{3}$ Department of Public Health, Marmara University Faculty of Medicine, İstanbul, Turkey
}

Background: Fractures are one of the main outcomes in osteoporosis and have an important effect on the general health status.

Aims: The purpose of this study was to determine the effect of major fracture history on quality of life. We also investigated the important risk factors and their effect on bone mineral density and fracture history.

Study Design: Cross-sectional study.

Methods: We recruited 105 patients who were admitted to an osteoporosis outpatient clinic. Medical history, family history, calcium intake, physical activity level and biochemical tests were evaluated. Lumbar spine and femur neck bone mineral density were measured. The Qualeffo- 41 questionnaire was also used for evaluating quality of life.

Results: The average age of the 105 patients included in the study was $56.04 \pm 13.73$ and $89 \%$ of them were post-menopausal women.
The average body mass index was $26.84 \pm 5.99$, which means that the women were overweight. Also, $48.5 \%$ of the patients were diagnosed with osteoporosis and $51.5 \%$ of them were diagnosed as low bone density. A total of 34 patients had a fracture history with minor trauma and some of the patients had more than one fracture (12 ankle and foot, 10 forearm, 9 vertebral, 4 hand, 3 hip, 2 rib, 1 tibial). When the patients with and without fracture history were compared, the mean Qualeffo-41 score in patients with fracture was $43.85 \pm 2.57$ and in the non-fracture group was $36.27 \pm 2.01$.

Conclusion: Forearm, ankle and foot fractures can be commonly seen in osteoporosis patients with fracture history. We suggest that it is important to recognise osteoporosis prior to first fracture and disease-specific quality of life assessment should be done.

Key Words: Fracture, Qualeffo-41, post-menopausal women
Osteoporosis (OP) is defined as systemic skeletal disease characterised by low bone mineral density and microarchitectural changes in the bone which increase its fragility and fracture risk. It is a progressive and silent disease until the first fracture occurs (1). Deterioration of bone quality and diminishing components of the bone increase the bone fragility. Around the world, 1 in 3 women and 1 in 5 men are at risk of an osteoporotic fracture. As the ageing population increases, $\mathrm{OP}$, which is one of the most common systemic chronic diseases, is becoming an important public health concern. In the United States, $54 \%$ of postmenopausal women have low bone density and 30\% have OP. Over 54 million people have been diagnosed with OP and 2 million OP-related fractures occur annually; fifty percent of them are vertebral fractures and the majority of other fractures are hip and wrist fractures. The economic burden of these fractures in healthcare is 17-20 billion dollars annually $(2,3)$.

Osteoporotic fractures affect the quality of life (QoL) in a negative way because of their effect on the musculoskeletal system and body posture; also, they cause pain and a decrease in functional capacity of OP patients. It has also been reported that $30 \%$ of women over 75 and $50 \%$ of women over 85 have non-traumatic vertebral fracture (4).

According to the World Health Organisation, QoL is defined as "individuals'perceptions of their position in life in the context of the culture and value systems in which they live and in relation to their goals, expectations, standards and concerns" (5). Although physical examination, imaging techniques and other assessment tools give an idea about the disease to the physician, they are poorly correlated with general well-being conditions and func-

This study was presented as a poster at the $12^{\text {th }}$ Congress of European Forum for Research in Rehabilitation, 11-14 September 2013, Istanbul, Turkey.

Address for Correspondence: Dr. Gülseren Akyüz, Department of Physical Medicine and Rehabilitation, Marmara University Faculty of Medicine, İstanbul, Turkey Phone: +902166254657 e-mail: gulserena@gmail.com

Received: 29.03.2014 Accepted: 11.07.2014 Available Online Date: 22.10.2014 • DOI: 10.5152/balkanmedj.2014.13265

Available at www.balkanmedicaljournal.org 
tional capacity (6). It is important to determine the related factors with chronic diseases and the evaluation of QoL is also indicated; this is gradually gaining importance in clinical studies (7).

Osteoporosis is a chronic disease which can cause negative impacts on well-being and QoL that result in physical, psychological and social restrictions (6). For this reason, we aimed to assess the QoL and related factors in OP patients who have macro-fractures or not and compare the results in our study. We also evaluated the relationship between fracture history with Vitamin $\mathrm{D}_{3}$ levels and bone mineral density (BMD), and also asked for other defined risk factors for $\mathrm{OP}$ and their effect on fracture history.

\section{MATERIALS AND METHODS}

\section{Study, subjects and participation}

In this cross-sectional study, we recruited 105 patients who admitted to osteoporosis polyclinics at the Department of Physical Medicine and Rehabilitation, Marmara University Hospital, between July and August 2013. Of the 158 patients assessed, only 105 were eligible for the study.

\section{Methods}

Approval of Marmara University Ethical Committee was taken and the procedures followed were in accordance with the ethical standards of the Declaration of Helsinki. The written informed consent form was taken from all participants. The patients were asked for age, height, weight, modifiable risk factors of OP, family history, previous fracture history (when, which bone and how many times), clothing type, Qualeffo-41 standard questionnaire. Routine laboratory tests, PTH, 25-OH Vitamin D levels (for excluding secondary OP) were also taken. Serum parathyroid hormone (PTH) was evaluated with ECLIA (electrochemiluminesence immune assay) technique and 25-OH Vitamin D was assessed with RIA technique. For biochemical tests after 12 hour fasting, the bloods were collected between 9.00 and 10.00 am $(6,8)$.

The BMD measurements were done by Dual-energy X-ray absorptiometry (DXA) (Lunar DPX-IQ, Lunar Corp, Madison WI, USA) in an anterior-posterior projection at the lumbar spine and femur neck. According to the World Health Organisation classification, a T score between -1 to -2.5 was accepted as low bone density and $\mathrm{T}$ score under -2.5 was also accepted as OP $(6,8)$.

\section{Quality of life assessment}

Qualeffo-41 is a specific questionnaire that is commonly used for the evaluation of QoL in patients with OP (9). It is validated for 20 languages including Turkish. In Qualeffo, there are 41 questions, and 5 subdomains. It is a self-administered test including pain, physical function, social function, general health perception, and mental function assessment. The Qualeffo-41 score interval is between 0-100 with a higher score indicating a lower QoL. In our study, we used the Turkish version of the Qualeffo-41 test (10).

\section{Statistical analysis}

Statistical analyses were done using Statistical Package for the Social Sciences v.15.0 (SPSS, Chicago, IL, USA). For descriptive results, mean $\pm \mathrm{SD}$ and percentages were given. The cases were grouped as fracture history existing or not; for categorical data, chi-square was used, and for group comparison, student-t test and non-parametric tests were used according to normal distribution analysis results. Pearson and Spearman correlation tests were also used. Multiple regression analysis was also done for significant correlations. The statistically significant level was determined as $\mathrm{p}<0.05$ and $95 \%$ confidence interval $(95 \% \mathrm{CI})$. Correlation coefficient between $0-0.25$ was accepted as no correlation, $0.25-0.50$ as low-medium correlation, $0.50-0.75$ as good correlation, and $0.75-1.00$ as excellent correlation (6).

\section{Diet and physical activity}

As modifiable risk factors for OP, calcium intake and physical activity were assessed according to the European Vertebral Osteoporosis Study (EVOS) questionnaire (11). Chronic diseases (hypertension, diabetes, coronary artery disease, chronic kidney insufficiency, asthma, rheumatic diseases) and drugs that can effect bone metabolism (1. Steroids; 2. Immunosuppressants; 3. Anti-epileptics; 4. Antacids; 5. Anxiolytics; 6.Thyroid hormones; 7. Anticoagulants; 8. Tamoxifen; 9. Insulin; 10. Diuretics; 11. Statins e.g.), smoking history, alcohol and tea consumption were also enquired about (8).

\section{RESULTS}

The mean age of 105 patients (101 female, 4 male) was $56.04 \pm 13.73$ years and the body mass index (BMI) was $26.64 \pm 5.99 \mathrm{~kg} / \mathrm{m}^{2}$. Overall, $43 \%$ of subjects were normal weight, $27 \%$ were overweight and $28 \%$ were obese. According to DXA scoring, $48.5 \%$ (50) were diagnosed as OP, and $51.5 \%$ (53) had low bone density. Mean number of fractures was $0.41 \pm 0.65(0-3)$. The descriptive data and some of the important laboratory results of patients are given in Table 1.

Those patients who had suffered a fracture previously ( 34 people) or not (71 people) were compared according to age, lactation period, BMI, number of births, DXA scores of Lumbar spine and femur neck score, 25-OH Vitamin D level, tea consumption, dairy consumption and physical activity score; there were no statistically significant differences $(p>0.05)$. When the subjects were evaluated according to risk factors, 
TABLE 1. Descriptive data of patients and laboratory results

\begin{tabular}{|c|c|c|c|}
\hline & Min & $\operatorname{Max}$ & Mean \pm SD \\
\hline Age & 21 & 87 & $56.04 \pm 13.73$ \\
\hline $\mathrm{BMI}\left(\mathrm{kg} / \mathrm{m}^{2}\right)$ & 14.00 & 56.30 & $26.84 \pm 5.99$ \\
\hline Number of birth & 0 & 12 & $2.95 \pm 2.61$ \\
\hline Lactation (years) & 0 & 20.0 & $2.78 \pm 3.47$ \\
\hline L1-L4 T Score & -5.80 & -.32 & $-2.32 \pm .99$ \\
\hline Femur neck T score & -4.10 & .10 & $-1.67 \pm .88$ \\
\hline ALP (IU/L) & 20.00 & 177.00 & $71.43 \pm 25.61$ \\
\hline $\mathrm{Ca}(\mathrm{mg} / \mathrm{dL})$ & 7.50 & 10.50 & $9.41 \pm .46$ \\
\hline $\mathrm{iCa}(\mathrm{mg} / \mathrm{dL})$ & 4.09 & 5.03 & $4.68 \pm .17$ \\
\hline $\mathrm{P}(\mathrm{mg} / \mathrm{dL})$ & 2.00 & 4.70 & $3.58 \pm .54$ \\
\hline PTH (pg/mL) & 16.40 & 533.00 & $60.61 \pm 58.09$ \\
\hline 25-OH-Vit D3 (mcg/L) & 4.51 & 117.00 & $40.09 \pm 21.93$ \\
\hline Fracture number & 0 & 3 & $.41 \pm .67$ \\
\hline Physical activity total score & 3 & 12 & $6.05 \pm 2.23$ \\
\hline Sport/Physical exercise score & 3 & 14 & $5.44 \pm 3.07$ \\
\hline Dairy consumption score & 3 & 12 & $7.61 \pm 2.63$ \\
\hline Coffee consumption (cup/day) & 0 & 6.00 & $.38 \pm .85$ \\
\hline Tea consumption (cup/day) & 0 & 20.00 & $4.48 \pm 3.98$ \\
\hline
\end{tabular}

SD: standard deviation; BMI: body mass index; ALP: alkaline phosphatase;

$\mathrm{Ca}$ : calcium; iCa: ionized calcium; P: phosphorus; PTH: parathyroid hormone

TABLE 2. Qualeffo-41 scores

\begin{tabular}{lccc}
\hline & Minimum & Maximum & Mean \pm SD \\
\hline Qualeffo-41 total score & 5.50 & 84.50 & $38.86 \pm 16.57$ \\
Pain score & 0 & 85.00 & $33.57 \pm 23.36$ \\
Physical functioning score & 0 & 82.30 & $28.36 \pm 19.85$ \\
Activities of daily living & 0 & 93.75 & $21.82 \pm 21.66$ \\
Jobs around the house & 0 & 100.00 & $32.50 \pm 27.37$ \\
Mobility & 0 & 75.00 & $28.61 \pm 18.99$ \\
Social & 0 & 100.00 & $54.19 \pm 25.13$ \\
General & 16.60 & 100.00 & $57.95 \pm 21.65$ \\
Mental & 0 & 83.30 & $47.98 \pm 18.75$ \\
\hline
\end{tabular}

SD: standard deviation

$20 \%$ were smokers. No alcohol consumption, anorexia nervosa or type $1 \mathrm{DM}$ was reported. There were $17(16.2 \%)$ rheumatoid arthritis (RA) patients, 16 (15.2\%) oophorectomised patients, $12(11.4 \%)$ with chronic obstructive pulmonary disease (COPD)/Asthma, 10 (9.5\%) with hypothyroidism, 9 (8.6\%) with early menopause, 5 (4.8) hyperthyroidism patients, 4 (3.8\%) with inflammatory bowel disease (IBD), 4 (3.8\%) with chronic liver disease, 3 (2.9\%) with hypogonadism, $3(2.9 \%)$ undergoing chemotherapy for breast cancer, 1 ankylosing spondylitis (AS) patient and 1 systemic lupus erythematosus (SLE) patient reported.

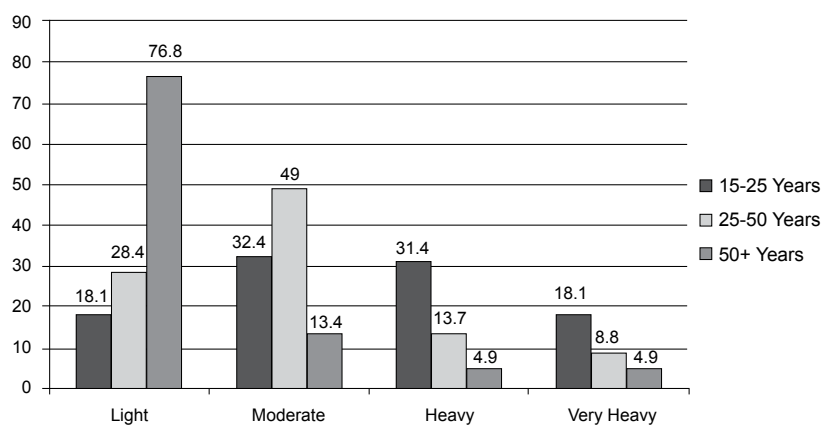

FIG. 1. Daily physical activity status according to age (Percentage)

When the medication history was evaluated, 30.5\% (32 people) of the patients were using antihypertensive agents, $25.7 \%$ (27 people) were using steroids, $13.3 \%$ (14 people) were using anti-diabetics, $10.5 \%$ (11 people) were using levothyroxine, $5.7 \%$ (6 people) were using hormone replacement therapy, and 2 were using anticonvulsants.

In total, 69 (65.7\%) patients were wearing traditional clothing, where only their hands and face are exposed to direct sunlight. Also, 37 (35.2\%) patients had a positive OP family history. There were $13(12.5 \%)$ patients with a hip fracture history in their families.

Fracture history after fall and/or mild trauma was positive in 34 people (32.7\%); 12 of them were foot/ankle bone, 10 were arm fractures, 9 of them were vertebral injuries, 4 of them were hand/wrist, 3 of them were hip, 2 of them were rib and 1 of them fractured 1 leg bone.

In those still having a menstrual cycle (16 people), 3 of them $(18.8 \%)$ reported menstrual irregularity. Overall, 84 patients $(80 \%)$ were in the post-menopausal stage. When current physical activity time per day was evaluated, $63.2 \%$ of patients were reported to do less than 30 minutes/day and only $9.5 \%$ of the patients exercised for more than 1 hour.

Patients with a positive fracture history had lower BMD and there was a significant relationship between OP and fracture history $(\mathrm{p}<0.05)$. Overall, $76.8 \%$ of patients above 50 years old reported a mild level of activity (Figure 1).

The subdomain scores of Qualeffo-41 were between $21.82 \pm 21.66$ and $57.95 \pm 21.65$. The most negatively affected subdomains in our study were general health perception $(57.95 \pm 21.65)$ and social function $(54.19 \pm 25.13)$ (Table 2). When we compared the Qualeffo-41 total scores in patients with or without fracture history, the mean score of the fracture group was 62.31 and that of the non-fracture group was 47.74 $(\mathrm{p}=0.021)$ (Table 3).

There were statistically significant correlations between Qualeffo-41 total score with BMI, PTH values, age, physical activity level and BMD (they were written according from the most to the least linear regression coefficient), as well as be- 
TABLE 3. Qualeffo- 41 subdomain comparison according to fracture history

\begin{tabular}{|c|c|c|c|c|}
\hline Fracture & & Mean \pm SD & & Mean \pm SD \\
\hline No & $\begin{array}{l}\text { Qualeffo-41 } \\
\text { Total score }\end{array}$ & $36.27 \pm 2.01$ & $\begin{array}{l}\text { Jobs around } \\
\text { the house }\end{array}$ & $29.82 \pm 3.27$ \\
\hline Yes & & $\begin{array}{c}43.85 \pm 2.57 \\
\mathrm{p}=0.021\end{array}$ & & $\begin{array}{c}37.35 \pm 4.65 \\
\mathrm{p}=0.141\end{array}$ \\
\hline No & Pain score & $31.62 \pm 2.97$ & Mobility & $25.36 \pm 2.20$ \\
\hline Yes & & $\begin{array}{c}37.09 \pm 3.42 \\
\mathrm{p}=0.181\end{array}$ & & $\begin{array}{c}33.69 \pm 3.17 \\
\mathrm{p}=0.04\end{array}$ \\
\hline No & $\begin{array}{l}\text { Physical } \\
\text { functioning score }\end{array}$ & $25.36 \pm 2.32$ & Social & $52.33 \pm 3.23$ \\
\hline Yes & & $\begin{array}{c}33.97 \pm 3.37 \\
\mathrm{p}=0.022\end{array}$ & & $\begin{array}{c}57.92 \pm 3.60 \\
\mathrm{p}=0.292\end{array}$ \\
\hline No & $\begin{array}{l}\text { Activities of } \\
\text { daily living }\end{array}$ & $19.13 \pm 2.47$ & Mental & $56.34 \pm 2.47$ \\
\hline Yes & & $\begin{array}{c}27.81 \pm 3.93 \\
\mathrm{p}=0.036\end{array}$ & & $\begin{array}{c}61.74 \pm 4.04 \\
p=0.03\end{array}$ \\
\hline No & $\begin{array}{l}\text { General health } \\
\text { perception }\end{array}$ & $56.34 \pm 2.47$ & & \\
\hline Yes & & $\begin{array}{c}61.74 \pm 4.04 \\
\mathrm{p}=0.206\end{array}$ & & \\
\hline
\end{tabular}

SD: standard deviation

tween fracture history with Qualeffo-41 total score, and physical and mental subdomain scores. Qualeffo-41 total score also reduced with increasing current daily walking time $(\mathrm{p}=0.002$ $\mathrm{r}=-0.310(* *))$ (Table 4$)$.

There were no significant differences between clothing type and 25-OH Vitamin D status, PTH, BMD.

\section{DISCUSSION}

Osteoporosis is a common public health problem that can cause disability; the first clinical manifestation is most frequently fracture. OP-related fractures are seen after low energy trauma and are usually located in certain regions. The most commonly seen ones are vertebral fractures. Only $30 \%$ of them have clinical symptoms, so it is mostly difficult to determine their prevalence. The second most common region for fractures is the hip and the third is distal forearm fractures in OP patients. There can be 20 years between fractures, which can alert the physician to upcoming events when the first fracture occurs. In our study, we detected 34 patients with fracture history. Dilek et al. (8) mentioned that foot and ankle fractures are as important as hand and wrist fractures, which are early signs of hip and vertebral fractures in OP. In patients without fracture symptoms, there could be subclinical vertebral fractures; it is very important to treat these in order to prevent other fractures. We know that vertebral fracture history increases the risk of new fracture by 4-5 times, independent of BMD. For this reason, determining those individuals who are at risk for OP makes the preventive approach more effective before the first fracture (8).

In our study, Qualeffo-41 total and subdomain scores of patients with fracture history were higher than patients without a fracture history. General health perception and social function subdomains of Qualeffo-41 were the most negatively affected. There was a significant correlation between Qualeffo- 41 total score with age, BMI, physical activity level, BMD and PTH levels. Sezer et al. (6) also reported the similar results in Turkish postmenopausal OP patients. Additionally, they found a positive correlation between Qualeffo-41 total score and BMI, number of births, menopause period, and a negative correlation between educational level, income, and femur neck BMD.

Metabolic syndrome could be a risk factor for OP related fractures (12). In our study, more than half of the patients were overweight or obese. Therefore, it is thought that higher BMI might be related to higher OP risk.

When the clothing types (modern and traditional group) were compared, there were no significant differences between serum 25-OH Vitamin D, PTH and BMD measurements. Sahin et al. reported that there were low serum Vitamin $\mathrm{D}_{3}$ levels in winter time in both the modern and traditional groups. This was related to seasonal factors and nutritional deficiencies. They concluded that the serum Vitamin $\mathrm{D}_{3}$ level difference between those groups could arise in summer time (13). Although we performed our study in the summer time, we could not show any difference between the serum Vitamin $\mathrm{D}_{3}$ levels, which were low in both groups. Food fortification with vitamin $\mathrm{D}$, serum Vitamin- $\mathrm{D}_{3}$ level screening, especially in certain age groups and postmenopausal women, and the early replacement of Vitamin $\mathrm{D}_{3}$, if necessary, could be solutions for this issue $(14,15)$.

\section{Quality of life}

Fractures are the main factors affecting the QoL of OP patients. As OP is commonly seen in elderly individuals, comorbidities make it even harder to cope with those fractures. Adachi et al. also reported similar results to those of our study, which indicate that fracture history is correlated with worse QoL. They also evaluated the QoL outcomes with multiple fracture types (16). According to their study, the worst QoL scores were in hip and pelvis fracture in women, and hip fracture in men. They found that hip fracture had the worst, wrist fracture had the best and vertebral fractures had moderate QoL scores in all OP patients (16). However, in our study, due to the lack of a sufficient number of patients in each fracture type group, we were unable to perform such an analysis.

Peker et al. (17) reported that age, menopause period, number of birth, and education in years correlated with BMD in 
TABLE 4. Correlation table of Qualeffo-41 scores with some risk factors

\begin{tabular}{|c|c|c|c|c|c|c|}
\hline & BMI & Age & PTH & L1-L4 T Score & Femur neck T score & Number of birth \\
\hline Qualeffo-41 total score & $\begin{array}{l}\mathrm{p}=0.013 \\
\mathrm{r}=0.248^{*}\end{array}$ & $\begin{array}{l}\mathrm{p}=0.001 \\
\mathrm{r}=0.312^{* *}\end{array}$ & $\begin{array}{l}\mathrm{p}=0.01 \\
\mathrm{r}=0.262 * *\end{array}$ & & $\begin{array}{l}\mathrm{p}=0.017 \\
\mathrm{r}=-0.236^{*}\end{array}$ & $\begin{array}{l}\mathrm{p}=0.007 \\
\mathrm{r}=0.268^{*}\end{array}$ \\
\hline Pain score & $\begin{array}{l}\mathrm{p}=0.04 \\
\mathrm{r}=0.206^{*}\end{array}$ & & & & & \\
\hline Physical Functioning score & $\begin{array}{l}\mathrm{p}=0.012 \\
\mathrm{r}=0.252 *\end{array}$ & $\begin{array}{l}\mathrm{p}=0.000 \\
\mathrm{r}=0.357^{*}\end{array}$ & $\begin{array}{l}\mathrm{p}=0.001 \\
\mathrm{r}=0.332 *\end{array}$ & $\begin{array}{l}\mathrm{p}=0.045 \\
\mathrm{r}=-0.198^{*}\end{array}$ & $\begin{array}{l}\mathrm{p}=0.013 \\
\mathrm{r}=-0.245^{*}\end{array}$ & $\begin{array}{l}\mathrm{p}=0.007 \\
\mathrm{r}=0.268 * *\end{array}$ \\
\hline Activities of daily living & $\begin{array}{l}\mathrm{p}=0.014 \\
\mathrm{r}=0.245^{*}\end{array}$ & $\begin{array}{l}\mathrm{p}=0.001 \\
\mathrm{r}=0.307 * *\end{array}$ & $\begin{array}{l}\mathrm{p}=0.000 \\
\mathrm{r}=0.357^{* *}\end{array}$ & & & $\begin{array}{l}\mathrm{p}=0.38 \\
\mathrm{r}=0.207^{*}\end{array}$ \\
\hline Jobs around the house & & $\begin{array}{l}\mathrm{p}=0.005 \\
\mathrm{r}=0.273^{*}\end{array}$ & $\begin{array}{l}\mathrm{p}=0.002 \\
\mathrm{r}=0.316^{* *}\end{array}$ & & & $\begin{array}{l}\mathrm{p}=0.009 \\
\mathrm{r}=0.259 * *\end{array}$ \\
\hline Mobility & $\begin{array}{l}\mathrm{p}=0.002 \\
\mathrm{r}=0.304 *\end{array}$ & $\begin{array}{l}\mathrm{p}=0.000 \\
\mathrm{r}=0.368^{*}\end{array}$ & $\begin{array}{l}\mathrm{p}=0.013 \\
\mathrm{r}=0.252^{*}\end{array}$ & & $\begin{array}{l}\mathrm{p}=0.018 \\
\mathrm{r}=-0.232\end{array}$ & $\begin{array}{l}\mathrm{p}=0.002 \\
\mathrm{r}=0.301 *\end{array}$ \\
\hline Social & & $\begin{array}{l}\mathrm{p}=0.002 \\
\mathrm{r}=0.293^{*}\end{array}$ & $\begin{array}{l}\mathrm{p}=0.017 \\
\mathrm{r}=0.242 *\end{array}$ & & $\begin{array}{l}\mathrm{p}=0.003 \\
\mathrm{r}=-0.295^{* *}\end{array}$ & $\begin{array}{l}\mathrm{p}=0.025 \\
\mathrm{r}=0.224^{*}\end{array}$ \\
\hline General & $\begin{array}{l}\mathrm{p}=0.011 \\
\mathrm{r}=0.254^{*}\end{array}$ & & & & & \\
\hline Mental & $\begin{array}{l}\mathrm{p}=0.035 \\
\mathrm{r}=0.211^{*}\end{array}$ & & & & & \\
\hline BMI & & $\begin{array}{l}\mathrm{p}=0.015 \\
\mathrm{r}=0.243^{*}\end{array}$ & & $\begin{array}{l}\mathrm{p}=0.002 \\
\mathrm{r}=0.312 * *\end{array}$ & & $\begin{array}{l}\mathrm{p}=0.001 \\
\mathrm{r}=0.341 * *\end{array}$ \\
\hline Dairy consumption & $\begin{array}{l}\mathrm{p}=0.005 \\
\mathrm{r}=0.316^{* *}\end{array}$ & & & $\begin{array}{l}\mathrm{p}=0.041 \\
\mathrm{r}=0.228^{*}\end{array}$ & & \\
\hline Lactation period (years) & $\begin{array}{l}\mathrm{p}=0.002 \\
\mathrm{r}=0.315 * *\end{array}$ & $\begin{array}{l}\mathrm{p}=0.000 \\
\mathrm{r}=0.506^{* *}\end{array}$ & & & & $\begin{array}{l}\mathrm{p}=0.000 \\
\mathrm{r}=0.826^{* *}\end{array}$ \\
\hline Number of birth & & $\begin{array}{l}\mathrm{p}=0.000 \\
\mathrm{r}=0.514^{* *}\end{array}$ & & $\begin{array}{l}\mathrm{p}=0.032 \\
\mathrm{r}=0.216^{*}\end{array}$ & & \\
\hline
\end{tabular}

SD: standard deviation; BMI: body mass index; PTH: parathyroid hormone

*: 0-0.25 no correlation, **: 0.25-0.50 low-medium correlation, ***: 0.50-0.75 good correlation,

****: 0.75-1.00 excellent correlation

women but the risk factors were insufficient to predict the low $\mathrm{BMD}$. These different results may come from the fact that $\mathrm{OP}$ is a multifactorial disease and there is a lack of determination of genetic factors in OP.

Adachi et al. (18) also showed that both vertebral and nonvertebral fractures negatively affect the QoL in OP patients. The QoL of patients with fracture history may be worse by the time of taking pharmacological treatment and it could be ignored by the clinicians. In the future, more of a focus on fracture-related outcome management should be planned, along with other interventions that would increase patients' satisfaction and QoL, should be considered (18).

Oleksik et al. (19) reported that QoL was negatively affected in patients with vertebral OP and a parallel increase between Qualeffo-41 scores and the number of fractures was found. In the study by Jackson et al. (20) in healthy postmenopausal women, they showed that calcium and vitamin D supplementation minimally increased the femur neck BMD. There were no reductions in fracture risk and it also did not increase the kidney stone occurrence. Cerrahoglu et al. (21) showed that dietary calcium intake diminished the bone loss, especially in trabecular bones, and that there was a positive relationship between dietary calcium intake and L1-L4 T score. However, there was no positive relation with femur neck BMD. In our study, we found a weak positive relationship between dairy intake frequency and L1-L4 T score, but there was no relationship with femur neck $\mathrm{T}$ score. Dairy intake frequency was positively correlated with higher BMI and QoL deterioration was found in that group. To prevent weight gain in postmenopausal women, dark green leafy vegetables, figs and other low calorie foods with high calcium content can be suggested. Regular physical exercises should also be recommended to increase bone quality and maintain a healthy weight $(22,23)$. As also shown in the study by Chen et al. (24), as shown by our results, there was no relationship between L1-L4 and femur neck T scores and tea consumption. There were also no effect of tea consumption on fracture history. 
OP-related fractures are common among population and it is very important to evaluate those who have risk factors before the first fracture occurs (25-27). Early diagnosis is the best way to preserve bone mass. Prescribing medications for OP and BMD follow-up is not enough. The patients should be informed about the disease and its complications. The therapeutic approach should include using pharmacological treatment, which helps to prevent bone loss and decrease the risk of fracture, in addition to lifestyle changes such as stopping harmful habituations (e.g. smoking, alcohol), doing more physical activity, and eating healthy foods. A rehabilitation program should also be designed for reducing pain, increasing functional capacity, and minimising the risk of falls. Also, social support should be given to those patients. Loneliness, depression and social isolation may cause introverted personality in these patients and decrease their future expectations about life. We suggest that psychological support should be added to medical treatment. As a result, the combination of all of these factors would reverse the disease progress and increase the quality of life. Further controlled and randomised clinical trials and population-based studies are needed in that area.

Ethics Committee Approval: Ethics committee approval was received for this study from Marmara University School of Medicine Local Ethics Committee.

Informed Consent: Written informed consent was obtained from patients who participated in this study.

Peer-review: Externally peer-reviewed.

Author contributions: Concept - P.K., G.A., E.L.; Design - P.K., G.A., E.L.; Supervision - G.A., E.L.; Resource - P.K., G.A.; Data Collection\&/or Processing - P.K., G.A., H.P.C., A.E.Ç., A.C., Ş.B., S.K., A.G.; Analysis\&/or Interpretation - P.K., G.A., M.Ö., E.L.; Liter ature Search - P.K., G.A.; Writing - P.K., G.A.; Critical Reviews - P.K., G.A.

Conflict of Interest: No conflict of interest was declared by the authors.

Financial Disclosure: The authors declared that this study has received no financial support.

\section{REFERENCES}

1. What is Osteoporosis? [Internet] [cited 2013 July 13]. Available from: http://www.osteofound.org/what-is-osteoporosis.

2. Skugor M. Osteoporosis. [Internet] [cited 2013 August 27]. Avaiable from: http://www.clevelandclinicmeded.com/medicalpubs/diseasemanagement/endocrinology/osteoporosis-disease/\#top.

3. Becker DJ, Kilgore ML, Morrisey MA. The societal burden of osteoporosis. Curr Rheumatol Rep 2010;12:186-91. [CrossRef]

4. Keskin D, Borman P, Eser F, Bodur H, Köse K. Evaluation of physical activity, bone mineral density and quality of life of elderly. Turk J Geriatr 2008;11:113-8.
5. World Health Organization, WHOQOL Measuring Quality of Life, 1997, Geneva. [Internet] [cited: 2013 July 13]. Available from: http:// www.who.int/mental_health/media/68.pdf.

6. Sezer N, Tomruk-Sutbeyaz S, Kibar S, Köseoğlu F, Aras M. Determinants of quality of life in postmenopausal osteoporosis. J PMR Sci 2009;12:19-25.

7. Akyüz G, Ofluoğlu D. Pain and quality of life in osteoporosis. In: Gökçe Kutsal Y. Osteoporoz. Modern Tıp Seminerleri: 19. Ankara: Güneş Kitabevi; 2001:204-11.

8. Dilek B, Baydar M, Sahin E, Uz B. The presence of osteoporosis and subclinical vertebral fracture in patients over 45 years of age with a fracture of the distal and of the radius. Turk J Phys Med Rehab 2012;58:220-4. [CrossRef]

9. Lips $Æ \mathrm{P}$, van Schoor MN. Quality of life in patients with osteoporosis. Osteoporos Int 2005;16:447-55. [CrossRef]

10. Kocyigit H, Gulseren S, Erol A, Hizli N, Memis A. The reliability and validity of Turkish version of quality of life questionnaire of the European Foundation for Osteoporosis (QUALEFFO). Clin Rheumatol 2003;22:18-23. [CrossRef]

11. Lunt M, Masaryk P, Scheidt-Nave C, Nijs J, Poor G, Pols H, et al. The effects of lifestyle, dietary dairy intake and diabetes on bone density and vertebral deformity prevalence: The EVOS study. Osteoporos Int 2001;12:688-98. [CrossRef]

12. von Muhlen D, Safii S, Jassal SK, Svartberg J, Barrett-Connor E. Associations between the metabolic syndrome and bone health in older men and women: The Rancho Bernardo Study. Osteoporos Int 2007:18:1337-44. [CrossRef]

13. Sahin Z, Kumbasar F, Yigit S, Yaman V, Turhan B, Kartal I. The effect of dressing style on vitamin D level in winter. Turkish Journal of Osteoporosis 2011;17:6-9.

14. Vitamin D and calcium: A systematic review of health outcomes, evidence report/technology assessment, Number 183, Agency for Healthcare Research and Quality (AHRQ) Publication No. 09-E015 Tufts Evidence-based Practice Center: August 2009.

15. Cranney A, Horsley T, O'Donnell S, Weiler H, Puil L, Ooi D, et al. Effectiveness and safety of vitamin D in relation to bone health. Evid Rep Technol Assess (Full Rep) 2007;1-235.

16. Adachi JD, Loannidis G, Berger C, Joseph L, Papaioannou A, Pickard L, et al. Canadian Multicentre Osteoporosis Study (CaMos) Research Group. The influence of osteoporotic fractures on health-related quality of life in community-dwelling men and women across Canada. Osteoporos Int 2001;12:903-8. [CrossRef]

17. Peker O, El O, Gulbahar S, Akalın E, Oncel S, Gökçe-Kutsal Y. The effects of life style and exercise habits on bone mineral density in postmenopausal period of women. Ege Fiz Tip Reh Der 2001;7:105-12.

18. Adachi JD, Ioannidis G, Olszynski WP, Brown JP, Hanley DA, Sebaldt RJ. The impact of incident vertebral and non-vertebral fractures on health related quality of life in postmenopausal women. BMC Musculoskelet Disord 2002;3:11. [CrossRef]

19. Oleksik A, Lips P, Dawson A, Minshall ME, Shen W, Cooper C, et al. Health-related quality of life in postmenopausal women with low BMD with or without prevalent vertebral fractures. $J$ Bone Miner Res 2000;15:1384-92. [CrossRef]

20. Jackson RD, LaCroix AZ, Gass M, Wallace RB, Robbins J, Lewis CE et al. calcium plus vitamin d supplementation and the risk of fractures. $N$ Engl J Med 2006;354:669-83. [CrossRef]

21. Cerrahoglu L, Duruoz MT, Tıkız C, Ölçenler S, Tulukoğlu N, Süsin A. The correlation between dietary calcium intake and bone mineral density in postmenopausal women. Turkish Journal of Osteoporosis 2002;8:173-7. 
22. Langsetmo L, Berger C, Kreiger N, Kovacs CS, Hanley DA, Jamal SA, et al. Calcium and vitamin D intake and mortality: Results from the canadian multicentre osteoporosis study (camos). J Clin Endocrinol Metab 2013;98:3010-8. [CrossRef]

23. Prevention and management of osteoporosis: Report of a WHO scientific group. (WHO technical report series; 921) World Health Organization Geneva: 2003.

24. Chen Z, Pettinger MB, Ritenbaugh C, LaCroix AZ, Robbins J, Caan BJ, et al. Habitual tea consumption and risk of osteoporosis: A prospective study in the women's health initiative observational cohort. Am J Epidemiol 2003;158:772-81. [CrossRef]
25. Watts NB, Bilezikian JP, Camacho PM, Greenspan SL, Haris ST, Hodgson SF, et al. American Association of Clinical Endocrinologists Medical Guidelines for Clinical Practise for the diagnosis and treatment of postmenopausal osteoporosis. Endocr Pract 2010;16(Suppl 3):S1-37. [CrossRef]

26. National Osteoporosis Foundation. Clinician's Guide to Prevention and Treatment of Osteoporosis. Washington, DC: National Osteoporosis Foundation; 2010.

27. Mauck KF, Clarke BL. Diagnosis, screening, prevention, and treatment of osteoporosis. Mayo Clin Proc 2006;81:662-72. [CrossRef] 